\title{
Bacteriological Differences Between COPD Exacerbation and Community-Acquired Pneumonia
}

\author{
Xue-Jun Li MD, Qi Li MD, Liang-Yi Si MD, and Qiao-Ying Yuan MD
}

\begin{abstract}
OBJECTIVE: To study the differences in pathogen distribution and antibiotic susceptibility between patients with COPD exacerbation and patients with community-acquired pneumonia, and develop guidance for antibiotic treatment of those conditions. METHODS: We retrospectively analyzed the medical records of 586 COPD-exacerbation patients and 345 community-acquiredpneumonia patients from January 2007 to December 2008, including sputum culture results, antibiotic susceptibilities of the microorganisms, and clinical characteristics. RESULTS: 276 (47\%) of the COPD-exacerbation patients, and $183(53 \%)$ of the community-acquired-pneumonia patients had a positive sputum culture. In order, the most common pathogens in the COPD-exacerbation patients were Pseudomonas aeruginosa, Escherichia coli, Klebsiella pneumoniae, Staphylococcus aureus, Acinetobacter baumannii, and Haemophilus influenzae. The most common pathogens in the community-acquired-pneumonia patients were Streptococcus pneumoniae, $\mathrm{H}$. influenzae, K. pneumoniae, $S$. aureus, and $E$. coli. CONCLUSIONS: $P$. aeruginosa was the most common pathogen in our patients with COPD exacerbation, and $S$. pneumoniae was the most common in our patients with community-acquired pneumonia. $P$. aeruginosa is especially common in the patients with serious or extremely serious COPD. Key words: COPD; exacerbation; community-acquired pneumonia; bacteriology. [Respir Care 2011;56(11):1818-1824. (C) 2011 Daedalus Enterprises]
\end{abstract}

\section{Introduction}

Community-acquired pneumonia refers to infected pulmonary parenchymal inflammation that is acquired outside the hospital, has a defined incubation period, and occurs within that average incubation period after entering the hospital. Community-acquired pneumonia is a common and important disease and a threat to human health; it is the first cause of death from infection. ${ }^{1}$ Changes in pathogens and increases in the antibiotic-resistance rate have caused many problems in the treatment of community-acquired pneumonia. ${ }^{2}$ Therefore, accurate and timely diagnosis and early treatment are key in prognosis.

The authors are affiliated with the Department of Geriatrics, Southwest Hospital, Third Military Medical University, Chongqing, China.

The authors have disclosed no conflicts of interest.

Correspondence: Xuejun Li MD, Department of Geriatrics, Third Military Medical University, Gao Tanyan Street 30, Sha Pingba District, Chongqing 400038, China. E-mail: lixuejun3@126.com.

DOI: $10.4187 /$ respcare.00915
COPD is a global disease with a very high incidence. According to China's epidemiological survey in 2002, the incidence of COPD in people over 40 years of age was $8.2 \%$. Every year millions of patients suffer COPD exacerbation, and more than 1 million people die of COPD. ${ }^{3}$ Thus far, the pathogenesis of COPD exacerbation has not been determined; some scholars believe that $80 \%$ of COPD exacerbation cases are caused by lower-respiratory-tract infection, and that $50-60 \%$ of the pathogens that cause COPD exacerbation are bacteria. ${ }^{4}$ Fanny et al found that the most frequent pathogens of COPD exacerbation were Streptococcus pneumoniae, Moraxella catarrhalis, Haemophilus influenzae, and Pseudomonas aeruginosa. ${ }^{5}$

COPD exacerbation and community-acquired pneumonia usually cause some of the symptoms of respiratorytract infections, such as fever, purulent sputum, an increase in white blood cells, and an increase in C-reactive protein. Additionally, COPD exacerbation often coexists with community-acquired pneumonia, and several studies have found that early-onset COPD exacerbation and community-acquired pneumonia have similar pathogenic spectrums. ${ }^{6}$ Both the American Thoracic Society and European Respiratory Society guidelines for the manage- 


\section{Bacteriological Differences Between COPD Exacerbation and Pneumonia}

ment of community-acquired pneumonia and COPD exacerbation comment on the analogous empirical antibiotic choices in the early stages of these 2 diseases. Therefore, the treatment of these diseases is similar. However, there are some bacteria differences between COPD exacerbation and community-acquired pneumonia when the severity of the diseases differs. ${ }^{7}$ We studied the differences in clinical features, etiologies, and antibiotic susceptibilities of the bacteria in patients with community-acquired pneumonia versus patients with COPD exacerbation, and provide a scientific basis for antibiotic selection.

\section{Methods}

This study was approved by the research ethics committee of Southwest Hospital, Third Military Medical University, Chongqing, China. The study was retrospective, so the research ethics committee waived the consent requirement.

\section{Study Population}

We retrospectively analyzed the medical records of patients with COPD exacerbation and community-acquiredpneumonia, treated at the Southwest Hospital of the Third Military Medical University, from January 2007 to December 2008. We searched our electronic medical records database with key words "exacerbation," "COPD," "chronic bronchitis," and "community acquired pneumonia." We included all patients who had microbiology results from sputum. We excluded patients who did not meet the COPD diagnostic criteria of the 2006 Global Initiative for Chronic Obstructive Lung Disease guidelines (postbronchodilator $\mathrm{FEV}_{1} / \mathrm{FVC}<0.70$ ). COPD exacerbation was diagnosed when a patient with background COPD presented with at least 2 of the following major symptoms: increased dyspnea, increased sputum purulence, and increased sputum volume. We excluded patients who were diagnosed with bronchiectasis or apparent consolidation on admission chest radiograph. Community-acquired pneumonia was defined as a new infiltrate on chest radiograph, and at least one major or two minor Fang criteria. ${ }^{8}$ Severe community-acquired pneumonia at the time of hospitalization was defined according to then-current American Thoracic Society guidelines. ${ }^{9}$ In the community-acquiredpneumonia group we excluded patients who had COPD.

\section{Data Collection}

From the medical records we collected data on patient age, sex, smoking history, home oxygen therapy, antibiotic and glucocorticoid use, admission arterial blood gas values, leukocyte count, body temperature, hospital days, and efficacy evaluation. We graded COPD severity according to the 2007 Global Initiative for Chronic Obstructive Lung Disease guidelines.

\section{Microbiological Evaluation}

Sputum specimens collected from expectoration, tracheal suctioning, or bronchoalveolar lavage were analyzed with standard procedures within 48 hours of admission. Microscopy was performed on Gram-stained smears. Sputum was cultured on 5\% horse blood agar and chocolate agar and incubated in $\mathrm{CO}_{2}$ for 24-48 hours. The isolates were tested for sensitivity to beta-lactams, a combination of beta-lactam and clavulanic acid, macrolides, and quinolones. Based on microscopy, only specimens representative of the lower respiratory tract were used. A representative lower-respiratory-tract sample was defined as containing $<25$ leukocytes and $>10$ epithelial cells per low-power field.

\section{Statistical Analysis}

Data are expressed as means $\pm \mathrm{SD}$. Categorical variables were analyzed with the chi-square test. A $P$ value of $<.05$ was considered significant. The analyses were performed with statistics software (SPSS 10.0, SPSS, Chicago, Illinois).

\section{Results}

\section{Clinical Features}

There were 875 episodes of COPD exacerbation, in 756 patients, from January 2007 to December 2008. We excluded 170 cases: 123 for pneumonia on initial chest radiograph, and 47 who did not have sputum-culture results. Thus, the COPD group included 586 patients with sputumculture results and without consolidation on initial chest radiograph. There were 418 men and 168 women, and this group's mean age was $75.3 \pm 8.4$ years.

In the community-acquired-pneumonia group there were 437 cases, 92 of which were excluded: 59 had been admitted within the previous 15 days, and 33 had severe immunosuppression from conditions such as neutropenia, human immunodeficiency virus infection, or solid-organ or bone-marrow transplant. There were 217 male cases and 128 female cases, and the mean age was $61.3 \pm 5.5$ years (Table 1).

The average age of the COPD patients was significantly higher than that of the community-acquired-pneumonia patients, and the COPD patients were predominantly male and contained a larger number of ex-smokers. More than 


\section{Bacteriological Differences Between COPD Exacerbation and Pneumonia}

Table 1. Subjects

\begin{tabular}{lccc}
\hline \hline & $\begin{array}{c}\text { COPD } \\
\text { Exacerbation } \\
(n=586)\end{array}$ & $\begin{array}{c}\text { Community- } \\
\text { Acquired } \\
\text { Pneumonia } \\
(n=345)\end{array}$ & $P$ \\
\hline Age (mean \pm SD y) & $75.3 \pm 8.4$ & $61.3 \pm 5.5$ & $<.001$ \\
Male, no. (\%) & $418(71)$ & $217(63)$ & .008 \\
Smoking History, no. (\%) & $89(15)$ & $89(26)$ & $<.001$ \\
$\quad$ Current smoker & $363(62)$ & $63(18)$ & $<.001$ \\
Ex-smoker & $134(23)$ & $193(56)$ & .02 \\
$\quad$ Non-smoker & $105(18)$ & 0 & \\
Home oxygen therapy, no. (\%) & & & \\
Corticosteroid use, no. (\%) & $87(15)$ & $11(3)$ & $<.001$ \\
$\quad \begin{array}{l}\text { Oral } \\
\text { Inhaled }\end{array}$ & $247(42)$ & 0 & \\
Antibiotics in the past week, & $216(37)$ & $85(25)$ & .03 \\
$\quad$ no. (\%) & & & \\
Admission in the past 3 months, & $160(27)$ & $23(13)$ & $<.001$ \\
$\quad$ no. (\%) & & & \\
\hline NA = not applicable & & & \\
\hline
\end{tabular}

$70 \%$ of the COPD patients had used corticosteroids. Respectively, $37 \%$ and $32 \%$ of the COPD-exacerbation and community-acquired-pneumonia patients had taken antibiotics within the week before hospitalization (Table 2).

\section{Microbiology}

Of the 586 COPD-exacerbation patients, there were 276 cases with positive sputum bacterial culture $(47 \%)$. We isolated 325 bacterial strains, and the top 5 pathogens were Klebsiella pneumoniae, S. pneumoniae, H. influenzae, $M$. catarrhalis, and $P$. aeruginosa. More than one bacterial strain was isolated from the sputum of 38 patients (7\%).

In the 345 community-acquired-pneumonia patients, there were 183 cases (53\%) with a positive sputum bacterial culture. We isolated 214 bacterial strains, and the top 5 pathogens were $S$. pneumoniae, $K$. pneumoniae, $H$. influenzae, Staphylococcus aureus, and P. aeruginosa. More than one bacterial strain was isolated in 17 patients (5\%). Tables 3 and 4 show the relationships between bacteria type and disease severity. Infections in patients with mild or moderate COPD were mainly caused by $S$. pneumoniae, which had an isolation rate of $45 \%$. P. aeruginosa played an important role in infections in patients with severe COPD, and had a bacterial isolation rate of $12 \%$. Acinetobacter baumannii was found only in patients with extremely severe COPD exacerbation. In the communityacquired-pneumonia patients, the isolation rate of Pneumococcus was higher than that of any other bacteria, and accounted for $28 \%$. In patients with severe communityacquired pneumonia the isolation rate of $S$. aureus was the highest $(27 \%)$ and was significantly higher than that of
Table 2. Admission Clinical Data

\begin{tabular}{|c|c|c|c|}
\hline & $\begin{array}{c}\text { COPD } \\
\text { Exacerbation } \\
(n=586)\end{array}$ & $\begin{array}{l}\text { Community- } \\
\text { Acquired } \\
\text { Pneumonia } \\
(n=345)\end{array}$ & $P$ \\
\hline Fever $\left(>38.0^{\circ} \mathrm{C}\right)$, no. $(\%)$ & $158(27)$ & $120(35)$ & .01 \\
\hline $\begin{array}{l}\text { Leukocyte count } \\
\qquad\left(\times 10^{3} \text { cells } / \mu \mathrm{L}\right)\end{array}$ & $12.3 \pm 4.1$ & $14.7 \pm 5.2$ & .053 \\
\hline Neutrophils (\%) & $75 \pm 15$ & $82 \pm 22$ & .55 \\
\hline $\mathrm{FEV}_{1}(\%$ predicted $)$ & $62 \pm 31.8$ & ND & NA \\
\hline Comorbidities, no. (\%) & $317(54)$ & $95(28)$ & $<.001$ \\
\hline Congestive heart failure & $112(19)$ & $48(14)$ & $<.001$ \\
\hline Coronary artery disease & $61(10)$ & $10(3)$ & $<.001$ \\
\hline Renal disease & $71(12)$ & $19(6)$ & .001 \\
\hline Liver disease & $18(3)$ & $17(5)$ & .15 \\
\hline Cerebrovascular accident & $105(18)$ & $51(15)$ & .22 \\
\hline Diabetes & $148(25)$ & $63(18)$ & .01 \\
\hline Others & $31(5)$ & $21(6)$ & .61 \\
\hline \multicolumn{4}{|l|}{ COPD Severity, no. (\%) } \\
\hline Mild & $62(11)$ & NA & NA \\
\hline Moderate & $270(46)$ & NA & NA \\
\hline Severe to very severe & $254(43)$ & NA & NA \\
\hline \multicolumn{4}{|l|}{$\begin{array}{l}\text { Community-Acquired Pneumonia } \\
\text { Severity Index, no. }(\%)\end{array}$} \\
\hline Class I or II & NA & $42(12)$ & NA \\
\hline Class III & NA & $210(61)$ & NA \\
\hline Class IV or V & NA & $93(27)$ & NA \\
\hline Mortality, no. (\%) & $57(10)$ & $23(7)$ & .11 \\
\hline Stay (d) & $16.7 \pm 3.8$ & $10.2 \pm 4.5$ & $<.001$ \\
\hline Mechanical ventilation, no. (\%) & $115(20)$ & $49(14)$ & .04 \\
\hline Noninvasive ventilation, no. (\%) & $110(19)$ & $39(9)$ & .003 \\
\hline $\begin{array}{l}\text { Admitted to intensive care unit, } \\
\text { no. }(\%)\end{array}$ & $20(3)$ & $14(4)$ & .61 \\
\hline $\begin{array}{l} \pm \text { values are mean } \pm S D \\
\mathrm{ND}=\text { no data collected } \\
\mathrm{NA}=\text { not applicable }\end{array}$ & & & \\
\hline
\end{tabular}

patients with mild or moderate community-acquired pneumonia.

According to experimental results from the 10 antibiotics, the sensitivity of $P$. aeruginosa to amikacin was greater than $70 \%$, and the sensitivities to meropenem and ceftazidime were approximately $66 \%$; the sensitivities to all the other tested antibiotics were lower. The sensitivity of the $P$. aeruginosa from the community-acquiredpneumonia patients was greater than that from COPDexacerbation patients, which could be because $P$. aeruginosa is isolated less often from community-acquired-pneumonia patients. In addition, multiple-drug-resistant $P$. aeruginosa accounted for approximately $40 \%$ of the communityacquired pneumonia cases (Table 5).

Figures 1 and 2 show the antimicrobial susceptibility of 47 sputum isolates of $P$. aeruginosa, and 90 sputum isolates of $S$. pneumoniae, respectively. 


\section{Bacteriological Differences Between COPD Exacerbation and Pneumonia}

Table 3. Sputum Bacteria Versus COPD Severity

\begin{tabular}{|c|c|c|c|c|}
\hline & \multicolumn{4}{|c|}{ COPD Severity Stage, no. (\%) } \\
\hline & $\begin{array}{c}\text { I or II } \\
\operatorname{FEV}_{1} 50-80 \% * \\
(n=29)\end{array}$ & $\begin{array}{c}\mathrm{III} \\
\mathrm{FEV}_{1} 30-50 \% * \\
(n=143)\end{array}$ & $\begin{array}{c}\mathrm{IV} \\
\mathrm{FEV}_{1}<30 \% * \\
(n=153)\end{array}$ & $\begin{array}{c}\text { All } \\
(n=325)\end{array}$ \\
\hline Streptococcus pneumoniae & $11(38)$ & $13(9)$ & $7(5)$ & $31(10)$ \\
\hline Staphylococcus aureus & $0(0)$ & $5(4)$ & $15(10)$ & $20(6)$ \\
\hline Haemophilus influenzae & $7(24)$ & $37(26)$ & $27(18)$ & $71(22)$ \\
\hline Klebsiella pneumoniae & $8(28)$ & $54(38)$ & $30(20)$ & $92(28)$ \\
\hline Escherichia coli & $0(0)$ & $5(4)$ & $6(4)$ & $11(3)$ \\
\hline Pseudomonas aeruginosa & $0(0)$ & $14(10)$ & $33(22)$ & $47(15)$ \\
\hline Acinetobacter baumannii & $0(0)$ & $0(0)$ & $23(15)$ & $23(7)$ \\
\hline Moraxella catarrhalis & $2(7)$ & $5(4)$ & $0(0)$ & $7(2)$ \\
\hline Other bacteria & $1(4)$ & $10(7)$ & $12(8)$ & $23(7)$ \\
\hline
\end{tabular}

Table 4. Sputum Bacteria Versus Community-Acquired Pneumonia Severity

\begin{tabular}{|c|c|c|c|c|}
\hline & \multicolumn{4}{|c|}{ Community-Acquired Pneumonia Severity Stage, no. (\%) } \\
\hline & $\begin{array}{c}\text { I or II } \\
(n=25)\end{array}$ & $\begin{array}{c}\text { III } \\
(n=125)\end{array}$ & $\begin{array}{l}\text { IV or V } \\
(n=64)\end{array}$ & $\begin{array}{c}\text { All } \\
(n=214)\end{array}$ \\
\hline Streptococcus pneumoniae & $12(48)$ & $35(28)$ & $6(9)$ & $53(25)$ \\
\hline Staphylococcus aureus & $0(0)$ & $10(8)$ & $17(27)$ & $27(13)$ \\
\hline Haemophilus influenzae & $4(16)$ & $32(26)$ & $12(19)$ & $48(22)$ \\
\hline Klebsiella pneumoniae & $7(28)$ & $33(26)$ & $11(17)$ & $51(24)$ \\
\hline Escherichia coli & $1(4)$ & $7(6)$ & $5(8)$ & $13(6)$ \\
\hline Pseudomonas aeruginosa & $0(0)$ & $1(1)$ & $6(9)$ & $7(3)$ \\
\hline Acinetobacter baumannii & $0(0)$ & $0(0)$ & $2(3.1)$ & $2(1)$ \\
\hline Moraxella catarrhalis & $1(4)$ & $5(4)$ & $1(2)$ & $7(3)$ \\
\hline Other bacteria & 0 & $2(2)$ & $4(6)$ & $6(3)$ \\
\hline
\end{tabular}

Table 5. Antibiotic Resistance of Bacteria in Our Subjects

\begin{tabular}{|c|c|c|c|c|}
\hline & $\begin{array}{c}\text { Community- } \\
\text { Acquired } \\
\text { Pneumonia } \\
\text { no. }(\%)\end{array}$ & $\begin{array}{c}\text { COPD } \\
\text { Exacerbation } \\
\text { no. }(\%)\end{array}$ & $\begin{array}{c}\text { Total } \\
\text { no. }(\%)\end{array}$ & $P$ \\
\hline \multicolumn{5}{|l|}{ Multiple Drug Resistance } \\
\hline Staphylococcus aureus & $14 / 21(67)$ & $19 / 27(70)$ & $33 / 48(69)$ & .78 \\
\hline Pseudomonas aeruginosa & $6 / 15(40)$ & $18 / 40(45)$ & $24 / 55(44)$ & .74 \\
\hline \multicolumn{5}{|l|}{$\begin{array}{l}\text { Resistance to Extended- } \\
\text { Spectrum Beta } \\
\text { Lactamase }\end{array}$} \\
\hline Escherichia coli & $8 / 13(62)$ & $7 / 11(64)$ & $15 / 24(63)$ & .63 \\
\hline Klebsiella pneumoniae & $21 / 58(36)$ & $29 / 78(37)$ & $50 / 136(37)$ & .91 \\
\hline
\end{tabular}

\section{Treatments and Outcomes}

The average hospitalization was $17.8 \pm 5.5$ days for the COPD-exacerbation patients and $13.3 \pm 6.1$ days for the community-acquired-pneumonia patients. The number and percentage of patients who needed mechanical ventilation

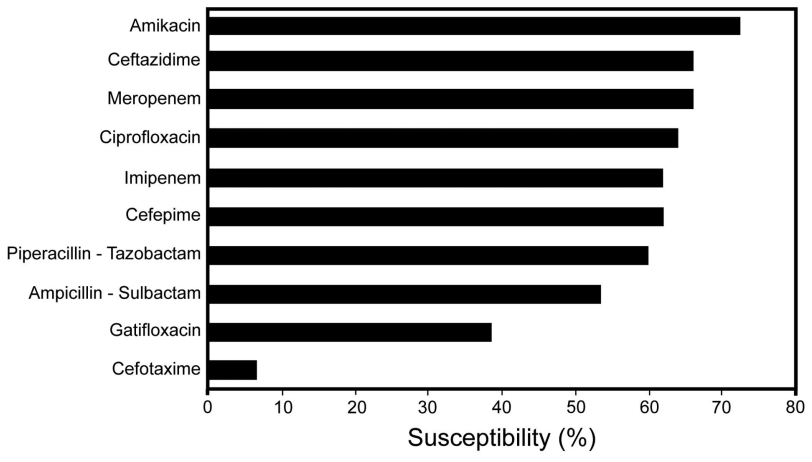

Fig. 1. Antimicrobial susceptibility of 47 sputum isolates of Pseudomonas aeruginosa.

in the COPD-exacerbation and community-acquired-pneumonia groups were 115/586 (20\%) and 49/345 (14\%), respectively, and that difference was significant. The death rates of the COPD-exacerbation and communityacquired-pneumonia groups were $10 \%$ and $7 \%$, respectively $(P<.01)$. 


\section{Bacteriological Differences Between COPD Exacerbation and Pneumonia}

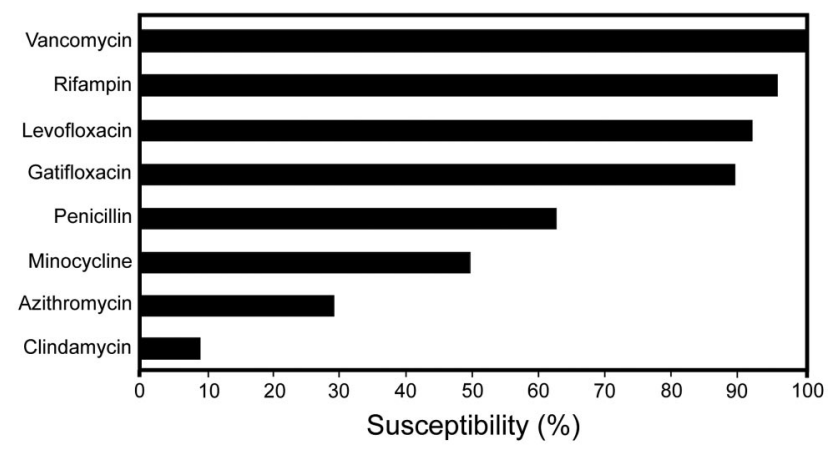

Fig. 2. Antimicrobial susceptibility of 90 sputum isolates of Streptococcus pneumoniae.

Table 6. Antibiotic Therapy

\begin{tabular}{lccc}
\hline \hline & $\begin{array}{c}\text { COPD } \\
\text { Exacerbation } \\
(n=586) \\
\text { no. }(\%)\end{array}$ & $\begin{array}{c}\text { Community- } \\
\text { Acquired } \\
\text { Pneumonia } \\
(n=345)\end{array}$ & $P$ \\
& $189(32)$ & $151(41)$ & $<.001$ \\
\hline no. $(\%)$ & \\
Macrolides & $61(10)$ & $48(13)$ & .11 \\
Third-generation cephalosporin & $205(35)$ & $101(27)$ & .07 \\
Semisynthetic penicillin & $131(22)$ & $49(13)$ & .002 \\
Carbapenems & $89(15)$ & $42(11)$ & .20 \\
Other* & $48(8)$ & $28(8)$ & .97 \\
Combination therapy & $124(21)$ & $51(14)$ & .03
\end{tabular}

* The other drugs included clindamycin, first-generation cephalosporins, second-generation cephalosporins, and aminoglycosides.

The most commonly used antibiotic among the community-acquired-pneumonia patients was respiratory quinolone, followed by third-generation cephalosporins (Table 6). The most commonly used antibiotic among the COPD-exacerbation patients was the third-generation cephalosporins, then respiratory quinolone. The use of carbapenem in the COPD-exacerbation group was significantly higher than that in the community-acquiredpneumonia group, and the COPD-exacerbation group received more combined antibiotic therapy than the community-acquired-pneumonia group $(P<.01)$.

\section{Discussion}

Both community-acquired pneumonia and COPD exacerbation have high morbidity and mortality and are caused by bacterial infections. Community-acquired pneumonia is the most common complication of COPD exacerbation. ${ }^{10}$ Some studies have carefully examined whether patients with community-acquired pneumonia and COPD present differences in clinical manifestations, etiology, or outcome, with special emphasis on mortality compared to those that do not have COPD. ${ }^{11,12}$ To our knowledge, the present study is the first to compare the clinical features, etiological distribution, and treatment outcomes of patients with COPD exacerbation versus patients with community-acquired pneumonia.

The COPD-exacerbation group was significantly older than the community-acquired-pneumonia group (64.7 \pm $8.4 \mathrm{y}$ vs $61.3 \pm 5.5 \mathrm{y}$ ), and there were significant differences in the ratios of sex, smoking, use of glucocorticoids (inhaled or oral), and antibiotics use before hospitalization between the 2 groups. Furthermore, the COPD-exacerbation patients had a higher ratio of mechanical ventilation than the community-acquired-pneumonia patients, the majority of whom needed noninvasive ventilation. All these clinical differences are in agreement with the clinical features of the two diseases. ${ }^{13}$

The rate of positive sputum culture in the COPDexacerbation patients was significantly lower than that in the community-acquired-pneumonia patients. This result might be explained by the fact that the ratio of viruses and atypical pathogens in COPD-exacerbation pathogens is higher than in community-acquired-pneumonia pathogens, and that the ratio of COPD-exacerbation patients who received antibiotics before hospitalization was significantly higher than in the community-acquired-pneumonia patients. ${ }^{14}$ The top 5 bacteria in the COPD-exacerbation patients were $K$. pneumoniae, $H$. influenzae, $P$. aeruginosa, $S$. pneumoniae, and $A$. baumannii. ${ }^{15}$ The top 5 bacteria in the community-acquired-pneumonia patients were S. pneumoniae, $K$. pneumoniae, $H$. influenzae, $S$. aureus, and Escherichia coli. ${ }^{16}$

Due to differences in disease severity, the bacterial distribution was significantly different between the 2 groups. $S$. pneumoniae, $K$. pneumoniae, and $H$. influenzae were the major bacteria in patients with mild COPD exacerbation, and each of those bacteria accounted for approximately $25 \%$. In the patients with severe COPD exacerbation the percentages of some non-fermenting bacteria (eg, $P$. aeruginosa and A. baumannii) were quite high (22\% and $15 \%$, respectively), whereas the percentage of $S$. pneumoniae was only $5 \%$. The etiological distribution in the community-acquired-pneumonia patients was different. S. pneumoniae was the most common species in all severity levels in the community-acquired pneumonia patients, and the total percentage was $28 \%$. The isolation rates of $K$. pneumoniae and $H$. influenzae in the level I-III community-acquired-pneumonia patients were both more than $25 \%$ of the isolation rate. S. aureus was the most common bacteria in the patients with level IV or greater communityacquired pneumonia, and accounted for about $25 \% .{ }^{17}$ The percentage of mixed infections that were caused by COPD exacerbation was slightly higher than those caused by community-acquired pneumonia. 


\section{Bacteriological Differences Between COPD Exacerbation and Pneumonia}

S. pneumoniae was the main pathogen in communityacquired pneumonia patients, and its isolation rate in the COPD-exacerbation patients was close to $10 \%$. The drugresistance rates of $S$. pneumoniae to penicillin and macrolide antibiotics could reach $42 \%$ and $90 \%$, respectively.

The isolation rate of $S$. aureus in patients with severe community-acquired pneumonia was the highest (about 25\%). The percentage of isolated methicillin-resistant S. aureus was $69 \%$. Therefore, the antibiotics used to treat severe community-acquired pneumonia should be effective against methicillin-resistant $S$. aureus.

$P$. aeruginosa was the common bacteria in severe and extremely severe COPD exacerbation and was especially common in older patients who had used antibiotics before hospitalization and needed a respirator. $P$. aeruginosa has also been found in some patients with severe communityacquired pneumonia. P. aeruginosa is more susceptible to amikacin than to any other drug, and hydrocarbon mold vinyl antibiotics are the next most effective. However, the susceptibilities are both less than $80 \%$. Because amikacin has a weaker sterilization effect in an acidic and hypoxic environment and could easily induce drug resistance if used alone, ${ }^{18}$ we used it with other drugs. The percentage of multiple-drug-resistant $P$. aeruginosa was relatively high, which might be due to the patients' advanced ages, comorbidities, long-term use of inhaled corticosteroids, a long hospitalization period, and the use of a respirator.

A. baumannii was found only in patients with extremely severe COPD exacerbation. Carbapenem antibiotics have the strongest effect in inhibiting A. baumannii's in vitro activity, but its sensitivity rate has decreased to $75 \%$. Of course, the sensitivity to any other antibiotic is even lower. We also found 2 pan-resistant strains of A. baumannii. The relevant percentages of extended-spectrum betalactamases produced by E. coli and $K$. pneumoniae were $63 \%$ and $37 \%$, respectively, which are significantly higher than the 35\% reported by Qiu et al. ${ }^{19}$ Our extendedspectrum beta-lactamases produced by $E$. coli and $K$. pneumoniae were mainly the TEM-X-type beta-lactamases, which is in agreement with a previous report. ${ }^{20}$ Presently, carbapenems are the most effective drugs for the treatment of E. coli and K. pneumoniae.

The mortalities of the COPD-exacerbation and community-acquired-pneumonia groups were $12 \%$ and $9 \%$, respectively. That difference is statistically significant and might be due to the advanced age, comorbidities, poor nutrition, and immunization conditions of the COPDexacerbation patients. The use of inhaled corticosteroid was not significantly associated with mortality in the COPD-exacerbation patients. ${ }^{21,22}$

Respiratory quinolone was the common antibiotic in both groups, used in more than a third of the cases. In recent years the drug resistance of $S$. pneumoniae has been rising, and the isolation rate of atypical pathogens in COPD- exacerbation patients and community-acquired pneumonia patients has increased. ${ }^{23}$ Additionally, with its good pharmacokinetic performance, high drug concentration in the lung tissue, long half-life, highly efficient bactericidal effect, broad antibiotic spectrum, low drug-resistance rate, safety, convenience, and good tolerance in patients, respiratory quinolone is being used more and more frequently. ${ }^{24}$ In contrast, because of problems such as inducing drug resistance and cross-resistance, third-generation cephalosporins are gradually being eliminated. The use of carbapenem in the COPD-exacerbation group was significantly higher than in the community-acquired-pneumonia group, and the COPD-exacerbation group received more combined antibiotic treatment than the communityacquired-pneumonia group $(P<.01)$. This might be because the COPD-exacerbation patients had a higher isolation rate of $P$. aeruginosa, A. baumannii, and other nonfermenting bacteria, a higher incidence of respirator use, and poorer basic patient conditions.

\section{Limitations}

The most important limitation was that the study population was in only one hospital and the cohort was primarily elderly and male, which may affect the representation of our findings. In addition, bacteria were identified with only one sputum culture, and there are more sensitive techniques we did not use. Because of the study's retrospective design, we may not have had the optimal clinical or laboratory data needed to evaluate clinical results. Further, multicenter prospective studies are needed to disclose the host-pathogen interaction that leads to COPD exacerbation and community-acquired pneumonia, to develop novel preventive and therapeutic approaches.

\section{Conclusions}

Bacteria was found in the sputum of more than half of the community-acquired-pneumonia patients and the COPD-exacerbation patients, but the bacterial isolation rate was lower in the patients who had used antibiotics before hospitalization. There were significant differences in the spectrum of bacteria in the community-acquiredpneumonia patients and the COPD-exacerbation patients with different disease severities. S. pneumoniae is the major pathogen of community-acquired pneumonia, whereas almost all COPD-exacerbation patients suffer from infections caused by Gram-negative bacilli. Respiratory quinolone can serve as the first-line drug for the empirical treatment of community-acquired pneumonia and COPD exacerbation, without the risk of infections from nonfermentative bacteria. ${ }^{25}$ Carbapenems are the most effective at inhibiting Gram-negative bacilli, but their sensitivity to carbapenems is decreasing, so carbapenem use should 


\section{Bacteriological Differences Between COPD Exacerbation and Pneumonia}

be strictly controlled. Combined antibiotic therapy might enhance the effect of treatment in patients with severe COPD exacerbation. These findings may influence the choice of empirical antibiotics in patients with COPD exacerbation or community-acquired pneumonia, according to disease severity. Multicenter prospective clinical research is required to determine reasonable treatment programs, improve prognosis, and develop novel preventive and therapeutic approaches for COPD exacerbation and community-acquired pneumonia.

\section{REFERENCES}

1. Chinese Center for Disease Control and Prevention. Report of chronic diseases in China 2006.

2. Diaz A, Barria P, Niederman M, Restrepo M, Dreyse J, Fuentes G, et al. Etiology of community-acquired pneumonia in hospitalized patients in Chile: the increasing prevalence of respiratory viruses among classic pathogens. Chest 2007;131(3):779-787.

3. Ko FW, Ng TK, Li TS, Fok JP, Chan MC, Wu AK, Hui DS. Sputum bacteriology in patients with acute exacerbations of COPD in Hong Kong. Respir Med 2005;99(4):454-460.

4. Mette V, Julie H, Susanne D, Alice F, Thomas R, Peter L. Bacteriology in acute exacerbation of chronic obstructive pulmonary disease in patients admitted to hospital. Scand J Infect Dis 2009;41(5): 26-32.

5. Fanny W, Margaret I, Paul K, Susanna S, Chau S, David S. A one-year prospective study of infectious etiology in patients hospitalized with acute exacerbations of COPD and concomitant pneumonia. Respir Med 2008;102(8):1109-1116.

6. Molions L, Clemente M, Miranda B, Alvarez C, Busto B, Cocina B, et al. Community-acquired pneumonia in patients with and without chronic obstructive pulmonary disease. J Infect 2009;58(4):417-424.

7. Restrepo M, Mortensen E, Pugh J, Anzueto A. COPD is associated with increased mortality in patients with community-aquired pneumonia. Eur Respir J 2006;28(1):346-351.

8. Fang G, Fine M, Orioff J, Arisumi D, Yu V, Kapoor W, et al. New and emerging etiologies for community-acquired pneumonia with implications for therapy. Medicine 1990;69(13):307-316.

9. Infectious Diseases Society of America/American Thoracic Society Consensus. Guidelines on the management of adults with community acquired pneumonia in adults. Clin Infect Dis 2007;44(Suppl): S27-S72.

10. Falguera M, Martin M, Ruiz-Gonzale A, Pifarre R, Garcia M. Community-acquired pneumonia as the initial manifestation of serious underline diseases. Am J Med 2005;118(23):378-383.
11. Torres A, Menendez R. Mortality in COPD patients with community-acquired pneumonia: who is the third partner? Eur Respir J 2006;28(4):262-263

12. Rello J, Rodriguez A, Torres A, Roig J, Sole V, Garnacho M, et al. Implications of COPD in patients admitted to the intensive care unit by community-acquired pneumonia. Eur Respir J 2006;27(5): 1210-1216.

13. Patel I, Seemungal T, Wilks M, Lloyd O, Donaldson G, Wedzicha J. Relationship between bacterial colonization and the frequency, character, and severity of COPD exacerbations. Thorax 2002;57(9): 759-764.

14. Ricard P, Miquel F, Carmina V, Antonio N. Characteristics of community-acquired pneumonia in patients with chronic obstructive pulmonary disease. Respir Med 2007;101(10):2139-2144.

15. Groenwegen K, Wouters E. Bacterial infections in patients requiring admission for an acute exacerbation of COPD. Respir Med 2003; 97(15):770-777.

16. Marrie T, Shariatzadeh M. Community-acquired pneumonia requiring admission to an intensive care unit. Medicine 2007;86(8):103111 .

17. Lim W, Lewis S, Macfarlane J. Severity prediction rules in community-acquired pneumonia: a validation study. Thorax 2000;55(7): 219-223.

18. Richard D, Robert P, Sydney M. Amikacin therapy for gramnegative septicemia. The Am J Med 1997;62(6):930-935.

19. Qiu Junfeng, Huang Kunrong, Wu Qian. Analysis of the monitorin resistance data of E. coli in recent three years. J Chongqing Medical Univer 2007;32(2):173-175.

20. Mu Xuekun, Chen Shengwen, Wang Shayan, Fu Yingyun'Lu Yuemei'Zhang Ruanzhang. Resistance and genetic testing on the ESBLs produced by Escherichia coli and Klebsiella pneumoniae. Chin J Infect Chemoth 2006;13(5):301-305.

21. Ernst P, Gonzalez AV, Brassard P, Sussa S. Inhaled corticosteroid use in COPD and the risk of hospitalization for pneumonia. Am J Respir Crit Care Med 2007;176(2):162-166.

22. Ernst P, Gonzalez AV, Brassard P, Suissa S. Inhaled corticosteroid use in chronic obstructive pulmonary disease and the risk of hospitalization for pneumonia. Am J Respir Crit Care Med 2007;176(2): 111-112.

23. Ko FW, Lam RK, Li TS, Fok JP, Chan MC, Ng TK, et al. Sputum bacteriology in patients hospitalized with acute exacerbations of chronic obstructive pulmonary disease and concomitant pneumonia in Hong Kong. Intern Med J 2005;35(11):661-667.

24. Woodhead M, Blasi F, Ewig S. Guidelines for the management of adult lower respiratory tract infections. Eur Respir J 2005;26(8): 1138-1180

25. Miyashita N, Matsushima T, Oka M. The ERS guidelines for the management of community-acquired pneumonia in adults: an update and new recommendation. Inter Med 2006;419-426. 